\title{
Experimental Investigation on TIG Welded Aluminium Alloy-6082 Weldment using Non-Destructive Evaluation
}

\author{
I. S. N. V. R Prashanth1, B. Manohar², K. Prudhvi Raj², P. Rohith² \\ ${ }^{1}$ Associate Professor, ${ }^{2}$ Student \\ 1,2Department of Mechanical Engineering, Guru Nanak Institute of Technology, Hyderabad, India
}

\begin{abstract}
How to cite this paper: I. S. N. V. R Prashanth | B. Manohar | K. Prudhvi Raj | P. Rohith "Experimental Investigation on TIG Welded Aluminium Alloy-6082 Weldment using Non-Destructive Evaluation" Published in International Journal of Trend in Scientific Research and Development (ijtsrd), ISSN: 24566470, Volume-3 I Issue-3, April 2019, pp.1047-1050, URL: https://www.ijtsrd.c om/papers/ijtsrd23

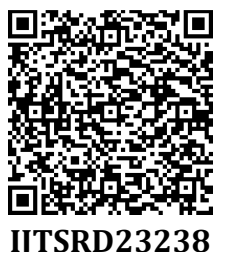
238.pdf

Copyright (C) 2019 by author(s) and International Journal of Trend in Scientific Research and Development Journal. This is an Open Access article distributed under the terms of the Creative Commons Attribution License (CC BY 4.0) (http://creativecommons.org/licenses/ by $/ 4.0$ )

\section{INTRODUCTION}

Non-destructive test as name itself implies that, it is a type of testing which is done without breaking the specimen or component, it used for detection of surface and sub-surface defects, to determine geometrical characteristics of material and in order to know composition, structure of material. This includes different testing's like visual inspection test, liquid penetrant test, magnetic particle test, ultrasonic test, radiography test and eddy current test these are all six basic and fundamental tests of non-destructive testings.

Visual inspection is the basic test which is conducted on material by this only surface defects which are visual to eyes are detected. Liquid penetrant test is used to detect defect at surface level only up to some depth from upper surface. Magnetic particle test detects the defects at sub-surface level, ultrasonic test also same as magnetic particle test defect detection but only difference is to equipment and defect detection accuracy. Radiography and eddy current testing are used to identify internal defects in material.

For complete production of any material it needs to pass different stages like design, fabrication, assembly and inspection or testing. In fabrication stage joining and finishing are included, for joining purpose rivets, welding and fasteners are used. For metal joining welding is used as permanent joint as welding is a joining process it joins two similar or dissimilar metals by application of pressure and heat on it. Different welding techniques are used for different application, in order to weld dissimilar metals tungsten inert gas welding is used.

During any fabrication process defects are emerged in component, for better results purpose these defects are prevented before application of this product in real time applications. In case of welding different defects are evolved like porosity, spatters, slag inclusions, lack of penetration, undercut, wrapping and distortion, weld crack and poor fusion.

Welding defects are prevented by providing sufficient power supply, use of good electrode and maintain proper speed of welding. If these are properly maintained during metal joining process most of the welding defects are eliminated.

In case of detection of weld defects in EN-08 TIG welded sheet the defects are detected like cluster porosity, slag inclusions. These defects are detected by liquid penetrant test and Magnetic particle test, Ultrasonic test also detect 
defects but not accurately as LPT and MPT, Radiography film gives good result compared to other as in case of EN-08 sample [5], Liquid penetrant test is one of the oldest and simplest NDT method where its earliest versions. This method is used to reveal surface discontinuities by bleed out of coloured or fluorescent dye from the flaw [9].

The magnetic measurement technique that was used allow us to record both structural change and cracks that results from fatigue degradation of high carbon pearlitic steel. In many cases if more than $80 \%$ of the life time is exhausted the dimensions of fatigue cracks do not exceed $1 \mathrm{~mm}$ [12].

The main trends in the inspection of objects for the purpose of detecting anomalies in the structures, constructions etc. It is the improvement of confidence during the detection of anomalies and enhancement of the application field of NDT instruments and technologies [13], The effect of various parameters such as accuracy, precision and sensitivity guide line that influence the selection of NDT technique were determined [8].

\section{Experimental Work}

\section{Materials}

Aluminium Alloys are extensively used in industries where light weighted materials are appreciated for its ability to reduce the self-weight while maintain the acquired strength of large components. For industries where design and detailed shaped components are of interest, aluminium alloys have the advantage of infinite range of possible section shapes due to extrusion techniques. They are used for their good mechanical properties (and therefore aswelded condition) and excellent corrosion resistance properties (particularly to stress corrosion cracking).

When considering Aluminium Alloys for Heat Exchangers, often there is even more benefit. The lower nickel content of the Aluminium grades means a better thermal conductivity as compared to the austenitic equivalent grade. Less heat transfer surface area is required to perform the same duty. Welding the Aluminium Alloys seems easy if the only criteria are passing ASME code, but consideration of the allimportant weld mixture and correct handling are needed to insure successful corrosion resistance.

Aluminium has different grades or series of alloys but for this project purpose aluminium- 6082 is used because its main feature is ability to resist the corrosion formation on material and as manganese content in this alloy increases its strength also increases due to grain control nature of manganese metal, it has wide variety of application where high stress bearing is needed it is used there.

\section{Welding of Test Specimens}

Welding is a joining process of metals which are same or different in chemical composition and structure, for this project tungsten inert gas welding (TIG) is selected because it produces weldments with less defects, dissimilar metals can also be welded and better control of process will takes place in this welding process.

TIG welding set-up contains different equipment's like tungsten electrode, power supply source and welding torch. In this welding process helium or argon gas used as shielding gas in order to prevent welding region by providing shield around welding arc, this will reduce effect of oxidation of materials during welding process. For this project $200 \times 170 \times 12 \mathrm{~mm}$ aluminium alloy-6082 is prepared and welded using TIG welding process.

\section{Testing of Test Specimen}

Every product after completion of fabrication needs to be tested in order to know its properties and defects in it, testing is done by two ways one is destructive test and other is non-destructive test. In this project TIG welded aluminium alloy-6082 sample specimens are tested by using nondestructive testings like liquid penetrant test, ultrasonic test and radiography test. These testing procedures are discussed briefly in coming sections.

\subsection{Liquid Penetrant Test:}

Liquid penetrant test is a basic test in non-destructive testing methods, but it has special feature that it detects surface defects with accurate manner, procedure for this test is discussed below

$>$ Cleaning of welding region by using cleaner which is chemical used for cleaning weldments only.

$>$ Application of penetrant on weld region as shown in Fig.1. this penetrant is colour and it is trapped inside the defects on the surface only.

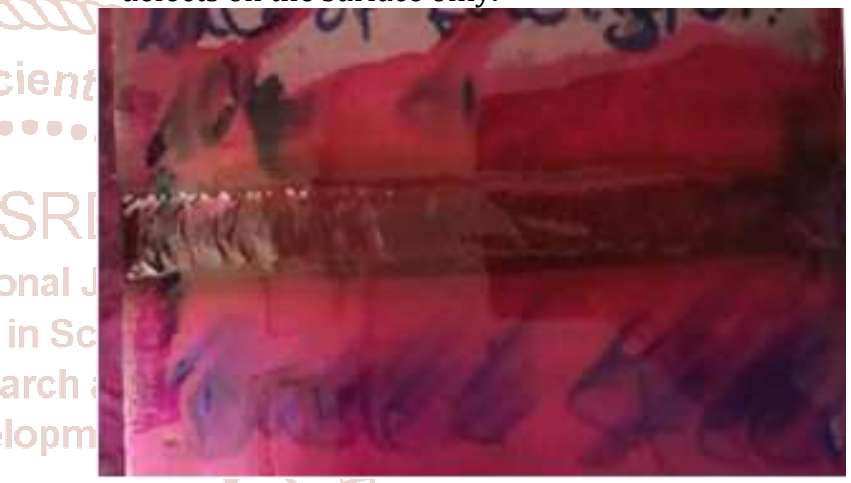

Fig.1. Penetrant Apllication on Weldment

Give time to weld region after application of penetrant in order to get better results from test by giving time more penetrant is trapped inside defects.

Application of developer as shown in Fig.2. it will take the penetrant where it trapped inside defects and results it as defect on that material.

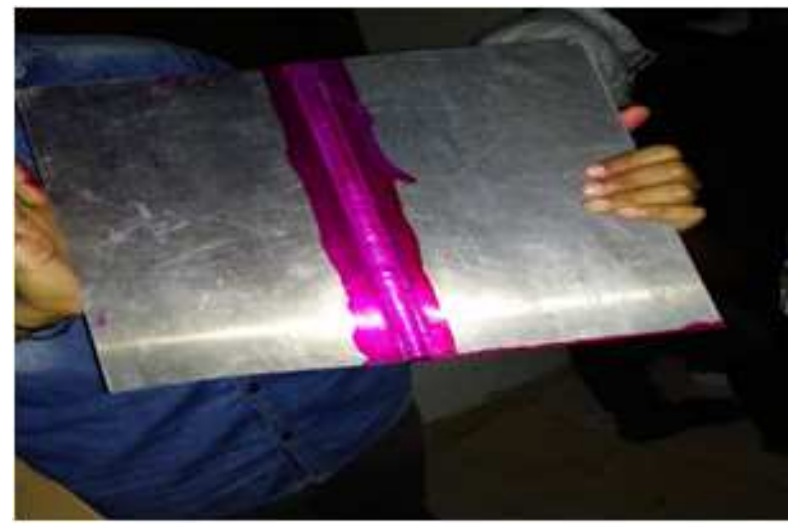

Fig.2. Developer Apllication on Weldment

\subsection{Ultrasonic Test:}

Ultrasonic test the name itself implies that use of sound waves for non-destructive testing of any material without breaking it, this test will detect the defects surface and subsurface level also, testing procedure for ultrasonic testing is discussed below 
International Journal of Trend in Scientific Research and Development (IJTSRD) @ www.ijtsrd.com eISSN: 2456-6470

$>$ First of ultrasonic testing equipment needs to be calibrated by using different calibrating blocks as shown in Fig.3.

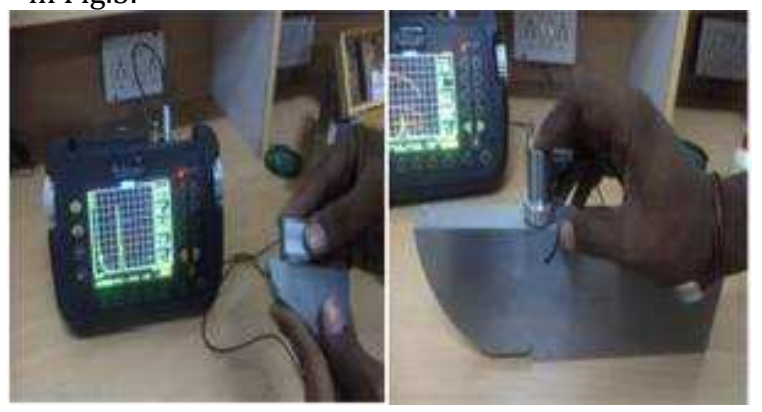

Fig.3. Calibration of Ultrasonic Equipment

> Apply couplant on test specimen it creates ait tight surface between probe and test specimen.

$>$ Place probe as shown in Fig.4. on test specimen and allow the ultrasound to strike weld region.

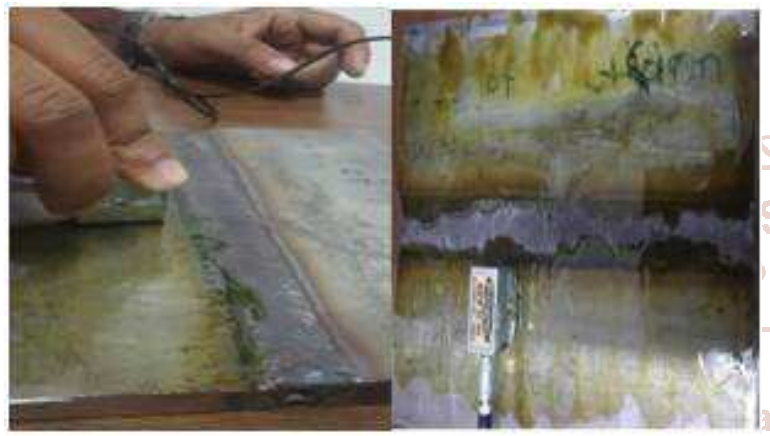

Fig.4. Testing of Specimen Bu Ultrasonic Probe

$>$ After striking it will get back to probe and receiver, here the time difference of sound wave before and after striking is considered,

$>$ On basis of sound echo and distance amplitude correction curves as shown in Fig.5. type of defect is identified.

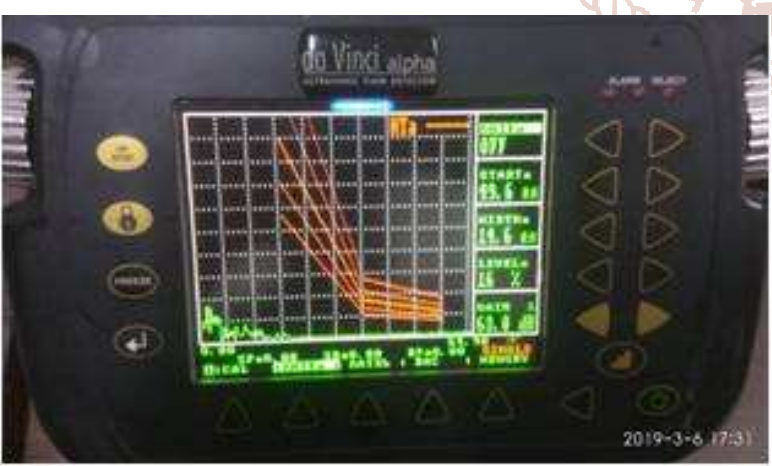

Fig.5. Distance Amplitude Correction Curves

\subsection{Radiography Test:}

Radiography test is used to detect internal defects like inclusions and internal flaws in weldment, this equipment consists of three different parts like radiation source, test specimen and sensing element, test procedure for this is discussed below

$>$ First test specimen is placed in experimental set-up.

$>$ Place sensing element beneath the test specimen in order to sense data from radiation.

$>$ Allow the gamma radiation to strike weld specimen, it will give photo film of test specimen on sensing element.

\section{Result and Discussion}

In this project three different testing are conducted on TIG welded aluminium alloy-6082 in order to identify and determine defects in it, the testings are liquid penetrant test, Ultrasonic test and radiography test, test results are discussed below

$>$ In liquid penetrant test on surface defects are detected, in this test specimen blow holes are detected as shown in Fig.6.

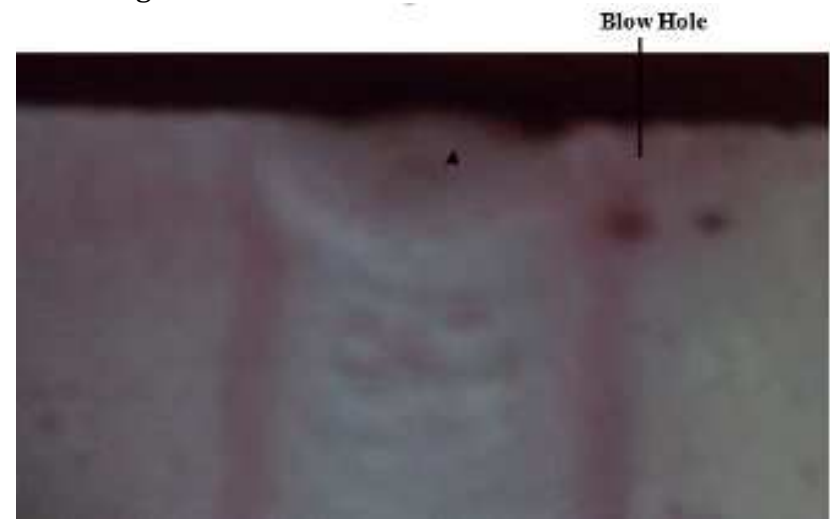

Fig.6. Blow Hole on Weldment

$>$ In ultrasonic testing inside flaws and porosity are detected, it is identified by flaw representation on distance amplitude correction cure as shown in Fig.7.

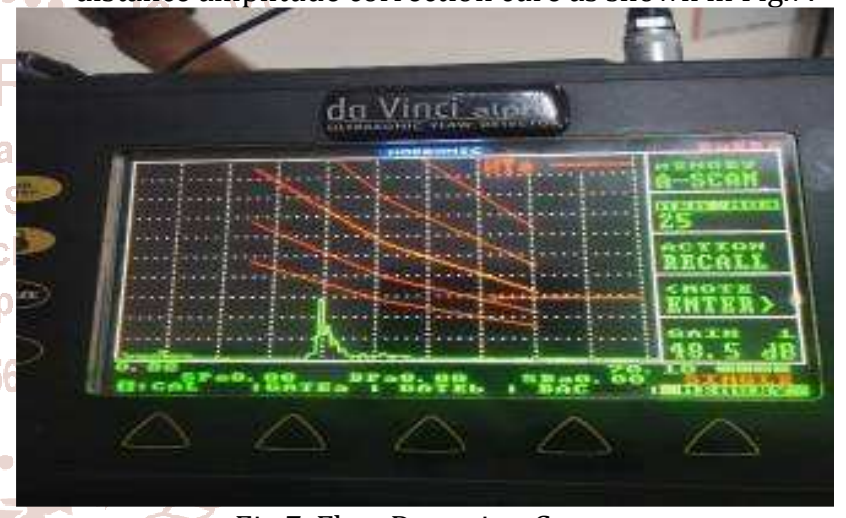

Fig.7. Flaw Detection Curve

> In radiography testing tungsten inclusion and porosity are detected are as shown in Fig.8.

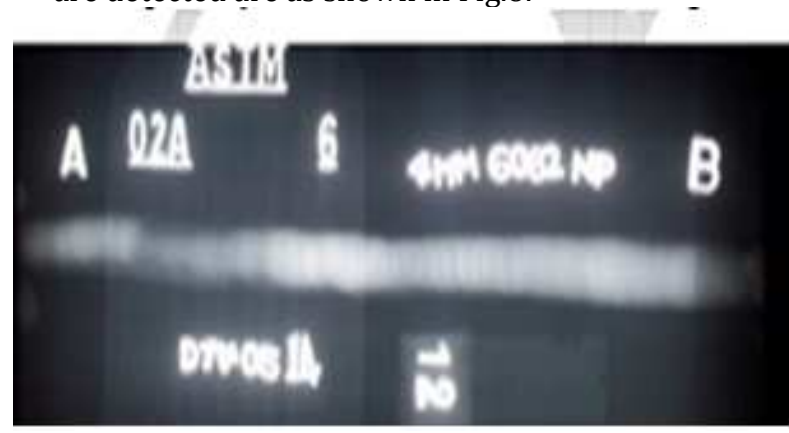

Fig.8. Inclusions on Radiography Film

\section{Conclusion}

Non-destructive testing of TIG welded aluminium alloy-6082 gives some conclusions about testing suitable for this material and effect of defects on this weldment, and they are discussed below

$>$ It was concluded that, liquid penetrant testing is more sensitive in detection of surface defects and this was an old and less expensive technique. Ultrasonic method is 
more sensitive in detection of internal defects. Radiography gave the images of internal defects. Finally, Ultrasonic phased array gave the accurate dimensions of porosity, which could not be detected by Radiography testing and Ultrasonic testing.

$>$ But the main defects in the aluminium alloy-6082 occurred while carrying TIG welding are inclusions and surface defects and the inclusions are mainly the internal defects which cannot be determined by the other NDT methods such as LPT and Ultrasonic test but can only be detected by Radiography.

$>$ It is also concluded that this material cannot be tested for Magnetic particle because of its non-magnetic nature which the result of presence of nickel and chromium.

$>$ Presence of this materials make the sample corrosive resistant and high strength.

$>$ It is also concluded that this aluminium alloy-6082 is suitable for heat exchangers and oil refineries as the defects are minimum and the material is corrosive resistance and high strength because of the mixture of austenite and ferrite.

\section{ACKNOWLEDGMENT}

I owe my immense thanks to my project Guide I. S. N. V. R PRASHATH, Associate professor DEPARTMENT OF MECHANICAL ENGINEERING Guru Nanak Institute of Technology for this sustained interest, constructive criticism and constant encouragement at every stage of this Endeavour.

Also, I heart fully thank Dr. B. Vijaya Kumar, professor and head of department, Guru Nanak Institute of Technology for his constant encouragement.
I extended my deep sense of gratitude to the principle Dr. S. Sreenatha Reddy and the management of Guru Nanak Institute of Technology for providing of the best amenities to enable us to complete my project in stipulated time.

\section{REFERENCES}

[1] S. V. Ranganayakulu, Samrat Goud Burra and B. Ramesh Kumar "Non-Destructive Evolution Study of Welded EN-08 Mild Steel Specimen” 2015.

[2] Shymji and Dr. Suresh Prasad "Non-Destructive Method by Penetrant Testing" International Journal of Advance Research, Ideas and Innovations in Technology, Vol. 3, No. 4, 2017, pp. 308-310.

[3] E. S. Gorkunov, R. A. Savrai, A. V. Makarov, S. M. Zadvorkin, and I. Yu. Malygina "Magnetic Inspection of Fatigue Degradation of a High-Carbon Pearlitic Steel" Russian Journal of Nondestructive Testing, Vol.47, No. 12, 2011, pp.803-809.

[4] V. I. Krainii, O. N. Budadin, and T. E. Ttoitskii-Markov "Increasing the Reliability of the Detection of Flaws in Complex Structures by Integrating the information of Multi parametric Nondestructive Testing" Russian Journal of Nondestructive Testing, Vol. 48, No.2, 2012, pp.115-122.

[5]/ S. V. Ranganayakulu, Samrat Goud Burra and Sanathana Ravi "Characterization of Weldments Defects Through Non-Destructive Evaluation Techniques" Indian Journal of Science and Technology, Vol. 10, No. 16, 2017, pp. 01-08. 